\title{
Specialized Optical Fiber Sensor for Nondestructive Intrinsic Quality Measurement of Averrhoa Carambola
}

\author{
Ahmad Fairuz OMAR ${ }^{*}$ and Mohd Zubir MATJAFRI \\ School of Physics, Universiti Sains Malaysia, 11800 Penang, Malaysia \\ *Corresponding author: Ahmad Fairuz OMAR_E-mail: thinker_academy@yahoo.com
}

\begin{abstract}
This paper presents an innovative and low-cost approach for nondestructive fruit quality analysis. The specialized optical fiber sensor developed and presented in this paper used a monochromatic wavelength, rather than a broad spectrum, to measure the intact carambola (star fruit) intrinsic quality, namely $\mathrm{pH}$ and firmness. The main objective of this research was to investigate the two optical fiber sensors used in this work, namely, the optical fiber red system (OF-RS) that operated with the peak sensitivity at $635 \mathrm{~nm}$ and the optical fiber near the infrared spectroscopy system (OF-NIRS) that operated with the peak sensitivity at $880 \mathrm{~nm}$. Both systems showed good accuracy in the $\mathrm{pH}$ and firmness measurement of the intact carambola with the correlation coefficient $R$ over 0.75 , and the measurement results were comparable with those of the commercial spectrometer. The best measurement results were obtained using OF- $\mathrm{RS}(\mathrm{pH}: R=0.876$; the root mean square error $(R M S E)=0.211 \mathrm{pH}$; firmness: $R=0.872 ; R M S E=0.909 \mathrm{kgf})$.
\end{abstract}

Keywords: Carambola, firmness, optical fiber sensor, pH, quality

Citation: Ahmad Fairuz OMAR and Mohd Zubir MATJAFRI, "Specialized Optical Fiber Sensor for Nondestructive Intrinsic Quality Measurement of Averrhoa Carambola," Photonic Sensors, DOI: 10.1007/s13320-013-0111-x.

\section{Introduction - transformation in fruit quality assessment}

For many decades, various efforts for fruit quality assessment have been theoretically and practically implemented. These efforts include the quality specification and instrumental measurement of the fruit quality [1]. A quality assessment system is required to ensure that the consumer purchases a fruit with the ideal quality [2]. Through continuous research, much progress has been achieved, and the agriculture industry has experienced transition in defining the term "quality" as well as the methodology of its interpretation. The current standard used in classifying the fruit quality is based on the size, shape, and presence and size of external damages [3]. Consequently, fruit properties that relate to sensory benefits, such as the chemical composition and texture, are not considered $[4,5]$. Realizing the importance of these parameters on consumers' acceptance, growers and distributors are developing company specifications that include relevant intrinsic properties acceptable to the consumers, such as the firmness and sugar and acid contents [3]. Currently, measuring these parameters usually requires destructive procedures and much labor and time. For that reason, a simpler, faster, and highly accurate measurement method is much preferred [6]. Chen, Sun [7] and Gao et al. [8] wrote a brief review listing the common methods and instruments that used for fruit quality assessment,

Received: 22 February 2013 / Revised version: 13 May 2013

(C) The Author(s) 2013. This article is published with open access at Springerlink.com 
such as the optical technique, machine vision technique, electrical technique, sonic vibration, nuclear magnetic resonance, electronic noses, and computed tomography. The optical method, particularly spectroscopy, is one of the most practical and most successful techniques for nondestructive measurement of the fruit quality due to its high-sensitivity detection, good adaptability, lightweight equipment, and flexible usage, and it is not harmful to people $[7,8]$; it has many advantages compared with the classical chemical and physical analytical methods [9].

Visible and near infrared (NIR) spectroscopy has been applied widely in the food industry, including the control and measurement of fruit and vegetable qualities [9, 10]. For instance, Fan et al. [11] conducted experiments to determine the soluble solid content (SSC) and firmness of apples using visible and NIR spectroscopy. In other recent spectroscopy applications in fruit quality assessment, Camps and Christen [12] measured the SSC, total acidity, and firmness of apricots, Cao et al. [13] measured the SSC and $\mathrm{pH}$ of grapes, Valente et al. [14] measured the firmness of mangoes, and Shao et al. [15] measured the SSC and $\mathrm{pH}$ of peaches. Meanwhile, Magzawa et al. [16] wrote a comprehensive review on the application of spectroscopy for internal and external quality analysis of citrus fruits. On the other hand, Sun et al. [17] concluded that visible and NIR spectroscopy was an excellent technology to assess the internal qualities of watermelons/melons and other fruits and, hence, was projected to play an important role in the research of online nondestructive techniques.

Commonly, in nondestructive fruit quality evaluation through spectroscopy using diode-array spectrometers, the measurement of the intrinsic parameters is conducted through the acquisition of broad spectra, which range from the visible up to the NIR wavelengths. A specific range of wavelengths represents the absorbance bands of a specific biochemical composition or color changes in the fruits at different stages of ripeness. Visible wavelengths between $672 \mathrm{~nm}$ and $676 \mathrm{~nm}$ are related to the chlorophyll contents of the fruits $[13,18,19]$. The NIR wavelengths usually used in the fruit intrinsic quality measurement are $950 \mathrm{~nm}, 960 \mathrm{~nm}$, $970 \mathrm{~nm}$, and $975 \mathrm{~nm}$, which are related to the water absorbance or O-H bands [19-24]. The $910 \mathrm{~nm}$ to $914 \mathrm{~nm}$ wavelengths are related to the SSC or the third overtone of the $\mathrm{C}-\mathrm{H}$ stretch $[6,24-26]$, and the $910 \mathrm{~nm}$ to $925 \mathrm{~nm}$ and $986 \mathrm{~nm}$ to $995 \mathrm{~nm}$ wavelengths are related to the $\mathrm{pH}[19,22,27]$. Certain spectral regions that do not contain valuable information about the chemical variations in the samples or contain irrelevant information such as the noise and background, which can worsen the measurement model, are neglected [28, 29]. The combination of the useful bands will result in better regression between the optical and actual values. Nonetheless, it is less economical and highly complicated when the measurement is performed only using a small number of selected wavelengths while neglecting the rest of the unused range of the measurement spectra. Inexpensive online sensors and instruments for nondestructive determination of the fruit intrinsic quality can be developed if the performance based on effective wavelengths could be close to or higher than whole spectra [13]. Chauchard et al. [30] claimed that, instead of relying on miniature holographic gratings or bandpass filters, such as the NIR imaging spectroscopy experiment by Tsuta et al [31] to measure the SSC in melons, using monochromatic light sources such as the light-emitting diode (LED) or laser diode to measure specific chemical components coupled to a silicon photodiode detector was another option. Chauchard et al. [30] stated that this was an ideal alternative because of the combination of the small size, low cost, and better robustness. Hence, this paper presents an innovative application of the optical fiber sensor that uses LEDs and photodetector for the measurement of the fruit intrinsic quality, namely, $\mathrm{pH}$ and firmness. At this point of the 
research, experiments have been conducted specifically on carambola (star fruit) from the B10 cultivar. The main objective of this paper is to identify the capability of the monochromatic optical fiber sensor in obtaining measurement accuracy that is comparable with that generated by commercial spectrometers.

\section{Materials and methods}

\subsection{Overview on the quality assessment of Carambola}

In Malaysia, for marketing purposes, the B10 carambola is classified according to seven different maturity indexes, as listed in Table 1; this classification is based on the color attributes. The grading process is currently being done manually by the Malaysian Federal Agricultural Marketing Authority (FAMA) through human visual identification, which is slow and inconsistent relative to the grading precision [32]. Because of a significant increase in the volume of B10 carambola production from 8,719 tons in 2005 to 16,915 tons in 2009 and 11,820 tons from January to June 2010 [33], efforts have been made by researchers to apply the latest technology for automatic carambola classification. Kamil et al. [32], Abdullah et al. [34], Abdullah et al. [35], and Amirulah et al. [36] have applied the machine vision technique using a charge-coupled device camera and image processing to classify carambola according to the FAMA standard index (Table 1). In addition to proposing an innovative and low-cost instrumentation for fruit

Table 1 Carambola specifications based on FAMA grading index "MS 1127, 2002" [37].

\begin{tabular}{cc|c}
\hline Index & \multicolumn{2}{c}{ Characteristics } \\
\hline Index 1 & Color & Maturity/Ripeness \\
Index 2 & Green with little yellowish & Immature \\
Index 3 & More green than yellow & Mature \\
Index 4 & Yellow-green & Mature \\
Index 5 & Yellow with a little green & Almost ripe \\
Index 6 & Yellow & Ripe \\
Index 7 & Orange & Ripe \\
\hline
\end{tabular}

quality analysis, this paper also redefines the term "quality" in the carambola classification, currently based on the physical properties (i.e., color, size, and shape), into intrinsic properties (i.e., $\mathrm{pH}$ and firmness).

\subsection{Determination of $\mathrm{pH}$ and firmness}

All the samples have to be tested for their actual quality attributes using a well-established instrumentation available commercially. The first intrinsic quality measurement conducted on the carambola samples was the firmness test using the Wagner FT Fruit Tester penetrometer with a full-scale measurement of $14 \mathrm{kgf}$ and a resolution of $0.1 \mathrm{kgf}$. The penetrometer was attached to the FT 516 tip [5/16" $(8 \mathrm{~mm})$ diameter]. The penetrometer was applied at $90^{\circ}$ of the fruit surface. The measurement was repeated at all five sides of the carambola sample. The average of all measurements was used to represent the firmness value of the fruit sample. After the fruit has been tested for its firmness, it was then cut into small cubes and pressed using a garlic squeezer, and its juice was collected in a 100-ml beaker. The acidity of the carambola was measured using the ExStik $\mathrm{pH}$ meter (PH100) from Extech Instruments (Waltham, Massachusetts, USA) with the measurement range between 0.00 and $14.00 \mathrm{pH}$, resolution of $0.01 \mathrm{pH}$, and accuracy of $\pm 0.01 \mathrm{pH}$. The $\mathrm{pH}$ meter was calibrated using a buffer solution with $\mathrm{pH}$ values of 7 and 4. Table 2 lists the characteristics of the carambola used in our research.

Table 2 Carambola samples used in this experiment.

\begin{tabular}{|c|c|c|c|c|}
\hline \multirow{2}{*}{ Sample } & \multicolumn{4}{|c|}{ Range } \\
\hline & $n$ & Weight (g) & Acidity $(\mathrm{pH})$ & Firmness (kgf) \\
\hline Carambola (B10) & 50 & $95.45-206.19$ & $2.41-4.12$ & $1.5-8.0$ \\
\hline
\end{tabular}

\subsection{Optical fiber sensor}

The innovative approach presented in this paper is through the application of the light source and a detector with the narrow emissive bandwidth and spectral sensitivity. The optical fiber red system 
(OF-RS) and optical fiber NIR system (OF-NIRS) have been developed to measure the carambola intrinsic quality. Similar to the typical reflectance/ absorbance spectroscopy experimental setup, the OF-RS and OF-NIRS also comprise a light source and a detector system. The OF-RS operates with the peak responsivity at $635 \mathrm{~nm}$, whereas the OF-NIRS operates with the peak responsivity at $880 \mathrm{~nm}$. The peak sensitivity definition is based on the peak emission wavelength of the LED, which is also closely related to the peak response of the optical sensor. The current limitation in the development of specialized optical fiber sensor is that only the restricted peak emission wavelengths and bandwidth of LEDs are available in the market. The same scenario also is applied in the selection of the optical detector, where the peak sensitivity is commonly available only at a certain and limited range. Despite these constraints, the measurement of the carambola intrinsic quality has been successfully conducted using the OF-RS and OF-NIRS, and a breakthrough that introduces a cost-effective, noninvasive measurement of the fruit intrinsic quality is presented in details in this paper.

The maximum efficiency of the optical measurement system can be achieved by matching accurately the source and the detector, particularly on their spectral response [38]. Therefore, selecting the light source and detector with ideal optical characteristics between each other is important. In this work, the OF-RS adopted the red LED "HLMP-EG08-WZ000" (AlInGaP emitter), which has a peak emissive wavelength at $635 \mathrm{~nm}$. The NIR LED "OPE5587" (high-speed GaAlAs infrared emitter) has a peak emission wavelength at $880 \mathrm{~nm}$.

For the optical fiber sensor design, two types of light detectors were used. The TSLR257, which has a high-sensitivity color light-to-voltage converter with a peak sensitivity at $635 \mathrm{~nm}$ and $670 \mathrm{~nm}$ (highest peak), was integrated into the OF-RS. On the other hand, the TSL267, which is a NIR light-to-voltage optical converter with a peak sensitivity at $900 \mathrm{~nm}$, was incorporated into the OF-NIRS. Both optical detectors used in this work came from a similar sensor family manufactured by TAOS Inc., which combined a photodiode and a transimpedance amplifier with a gain of $320 \mathrm{M} \Omega$ on a single CMOS IC. The TSLR257 detector was equipped with a color filter over the photodiode, whereas the TSL267 was equipped with a visible light blocking plastic side-looker package with an integral lens.

In the development of the OF-RS and OF-NIRS, a photodetector was connected to the instrumentation amplifier (INA122) with either five or ten voltage amplification gains. Five voltage amplification gains could be achieved by leaving both $\mathrm{R}_{\mathrm{G}}$ pins on the INA122 open, whereas ten amplification gains could be obtained by connecting a 40-k $\Omega$ resistor between the $\mathrm{R}_{\mathrm{G}}$ pins. However, for the experiment on carambola quality measurement, the amplification gain was set to five for the optimum result. The amplification result at the output port was connected to a 12-bit serial analog-to-digital converter (MCP3202). The signal processing and data display were controlled by the Basic Stamp 2pe (BS2pe) microcontroller. The Basic Stamp 2pe motherboard (dimension: $69.9 \mathrm{~mm}$ $\times 34.3 \mathrm{~mm}$ ) was used for data processing, which was capable of displaying the final result (ADC output) onto a four-digit, seven-segment display. The complete system circuit design is shown in Fig. 1. The circuit shown represents the OF-RS and OF-NIRS.

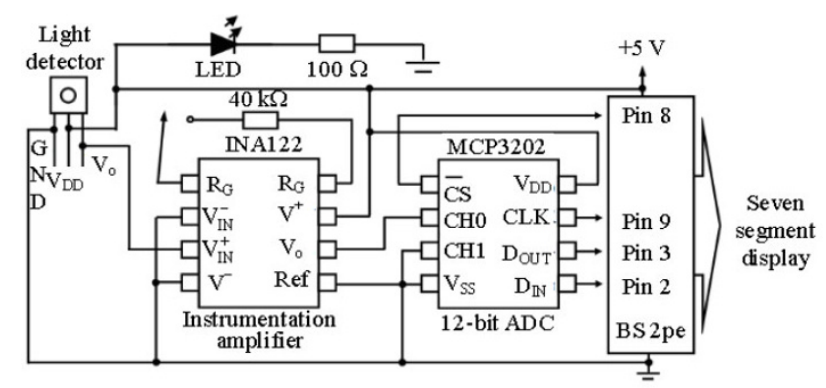

Fig. 1 Circuit diagram for the optical fiber system developed for carambola quality measurement. 


\subsection{Jaz spectrometer}

Although every LED and the photodetector are considered for their peak wavelengths, these components actually have broad spectral characteristics. Therefore, we must understand how the individual wavelength within the spectral range of the LED and the detector used in this research responds to the quantification of $\mathrm{pH}$ and firmness of the carambola. Hence, the Jaz spectrometer from Ocean Optics Inc. $(\lambda=200 \mathrm{~nm}$ and $1,100 \mathrm{~nm})$ and the tungsten halogen lamp with a spectral emission between $360 \mathrm{~nm}$ and $2,000 \mathrm{~nm}$ were used for comparative analysis. During the calibration, the measurement probe was located at $5 \mathrm{~cm}$ from the surface of the standard white reference while during the measurement on the intact carambola, the probe was located right on the top of the sample as shown by Fig. 2. The SpectraSuite software was then used to convert the raw spectra into reflectance as represented by (1). The value of reflectance at the selected individual wavelength $(\lambda: 600 \mathrm{~nm}-700 \mathrm{~nm}$ $\& \lambda: 830 \mathrm{~nm}-930 \mathrm{~nm}$ ) was then correlated with the value of carambola $\mathrm{pH}$ and firmness.

$$
R_{\lambda}=\frac{S_{\lambda}-D_{\lambda}}{R_{\lambda}-D_{\lambda}} \times 100
$$

where,

$S_{\lambda}=$ the sample intensity at the wavelength $\lambda$;

$D_{\lambda}=$ the dark intensity at the wavelength $\lambda$;

$R_{\lambda}=$ the reference intensity at the wavelength $\lambda$.

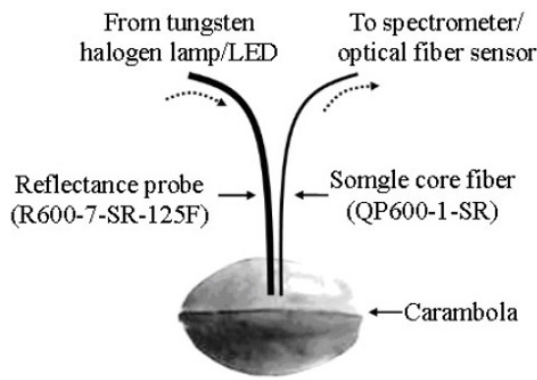

Fig. 2 Experimental setup for carambola quality measurement through the spectrometer and optical fiber sensor.

\subsection{Experimental setup}

Figure 2 shows the experimental setup for the measurement of the carambola intrinsic quality through the optical fiber sensor (Fig. 3) as well as the spectrometer via the interactance mode. The reflectance measurement mode did not produce any results in the measurement, which was most probably because of the glossy carambola surface that led to the high specular reflection and minimized the actual signal produced diffusely by the fruit. Furthermore, due to the limited penetration depth of the NIR radiation into the fruit, the reflectance spectra did not contain much information about the internal quality of the flesh [16, 39]. This problem was solved with the implementation of the interactance measurement mode, done by allowing the light to enter directly into the fruit, and the retrieval of the resultant light was made at a distance from the emission probe. In other words, the field of view of the detector was separated from the illuminated surface [40].

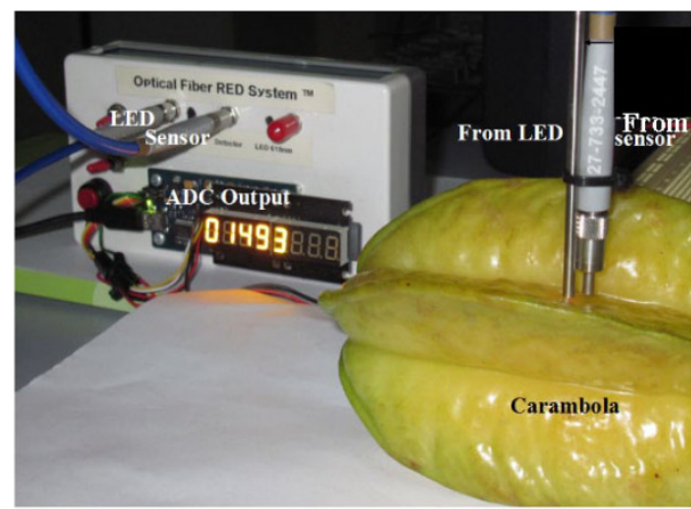

Fig. 3 Experimental setup using the optical fiber red system.

The accuracy of the regression models was calculated using the correlation coefficient, $R$, and root mean square of error, RMSE (in $\mathrm{pH}$ for acidity and kgf for firmness) using (2) and (3).

The coefficient of determination is expressed as

$$
R=\sqrt{\frac{\left[n \sum x y-\left(\sum x\right)\left(\sum y\right)\right]^{2}}{\left[n \sum x^{2}-\left(\sum x\right)^{2}\right]\left[n \sum y^{2}-\left(\sum y\right)^{2}\right]}}
$$

where $x$ is the independent variable, and $y$ is the dependent variable.

The root mean square of error is expressed as

$$
R M S E=\sqrt{\frac{\sum(y-Y)^{2}}{n-1}}
$$


where $n$ is the number of data points, and $Y$ is the predicted $y$-value.

\section{Results and analysis}

The first part of this section presents the results from the interactance measurement of the $\mathrm{pH}$ and firmness of the intact carambola using the Jaz spectrometer, whereas the second part elaborates on the result obtained using the optical fiber sensors. Figure 4 shows the relationship between the linear correlation coefficient and the individual wavelengths between $600 \mathrm{~nm}$ and $700 \mathrm{~nm}$ in quantifying the carambola $\mathrm{pH}$ and firmness. From the graph shown in Fig. 4, for the $\mathrm{pH}$ measurement, the wavelengths between $655 \mathrm{~nm}$ and $685 \mathrm{~nm}$ produce a high correlation coefficient $R$ over 0.85 with a peak response at $675 \mathrm{~nm}(R=0.876)$. For the firmness measurement, the wavelengths between $615 \mathrm{~nm}$ and $690 \mathrm{~nm}$ produce a high $R$ (over 0.8 ) with a peak response at $660 \mathrm{~nm}(R=0.873)$. For the measurement of both parameters, a drastic drop in $R$ is observed for the wavelength beyond $690 \mathrm{~nm}$. Overall, similarities are observed in the response curve between the $\mathrm{pH}$ and firmness measurement. The firmness measurement shows a better response compared with that of the $\mathrm{pH}$ for wavelengths between $600 \mathrm{~nm}$ and $660 \mathrm{~nm}$, whereas for wavelengths between $665 \mathrm{~nm}$ and $700 \mathrm{~nm}$, the $\mathrm{pH}$ measurement shows a better response compared with that of the firmness. The OF-RS operated within this wavelength range, with the LED peak emission at $635 \mathrm{~nm}$ and detector peak response at $670 \mathrm{~nm}$ (with $635 \mathrm{~nm}$ as the second peak response).

Figure 5 shows the relationship between the coefficient of the determination and individual wavelengths between $830 \mathrm{~nm}$ and $930 \mathrm{~nm}$ in quantifying the carambola $\mathrm{pH}$ and firmness measured using the Jaz spectrometer. In contrast to the measurement shown in Fig. 4 where $R$ was generated by linear regression, for the NIR region shown in Fig. 5, $R$ for the $\mathrm{pH}$ was best generated by quadratic regression, whereas for firmness, $R$ was generated by cubic regression. For the $\mathrm{pH}$ measurement, the $R$ value increased with higher wavelength values, and for the range examined in this paper, the peak was located at $930 \mathrm{~nm}(R=$ 0.784). A higher NIR value was closely related to the water absorbance band. For the firmness measurement, the $R$ value remained relatively the same and fluctuated between 0.783 and 0.789 , with the peak located at $890 \mathrm{~nm}(R=0.789)$. The OF-NIRS operated within this wavelength range with the LED peak emission at $880 \mathrm{~nm}$ and detector peak response at $900 \mathrm{~nm}$.

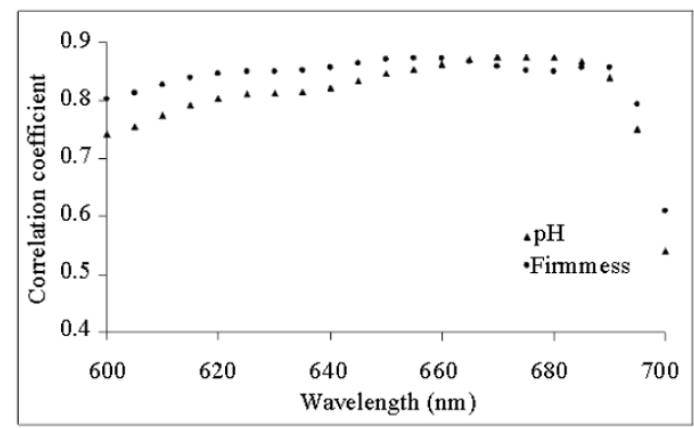

Fig. 4 Relationship between the linear correlation coefficient and individual wavelengths between $600 \mathrm{~nm}$ and $700 \mathrm{~nm}$ in quantifying carambola $\mathrm{pH}$ and firmness measured using the interactance technique via the Jaz spectrometer.

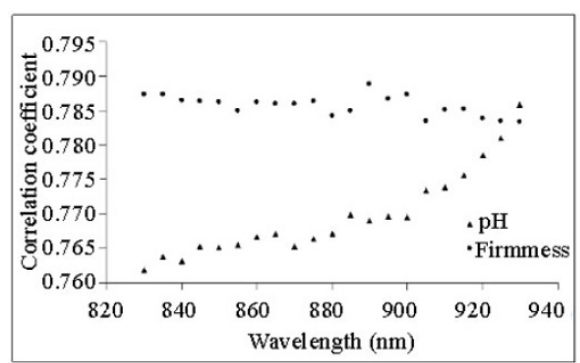

Fig. 5 Relationship between the correlation coefficient and individual wavelengths between $830 \mathrm{~nm}$ and $930 \mathrm{~nm}$ in quantifying carambola $\mathrm{pH}$ (quadratic $R$ ) and firmness (cubic $R$ ) measured using the interactance technique via the Jaz spectrometer).

After the measurement using the spectrometer has been completed, similar measurement was then conducted using the OF-RS and OF-NIRS. For the $\mathrm{pH}$ measurement, the response algorithm was generated by linear and quadratic regression (Fig. 6). The linear representation of the carambola $\mathrm{pH}$ 
measurement is expressed in (4) with $R=0.861$ and RMSE $=0.22 \mathrm{pH}$. The quadratic regression generated better correlation for the $\mathrm{pH}$ measurement with $R=0.876$ and $R M S E=0.211 \mathrm{pH}$, as expressed in (5).

$$
\begin{gathered}
p H=0.424+0.00162 R_{635} \\
R=0.861 ; R M S E=0.220 \mathrm{pH} \\
p H=4.177-0.003016 R_{635}+0.000001 R_{635}{ }^{2} \\
R=0.876 ; R M S E=0.211 \mathrm{pH} .
\end{gathered}
$$

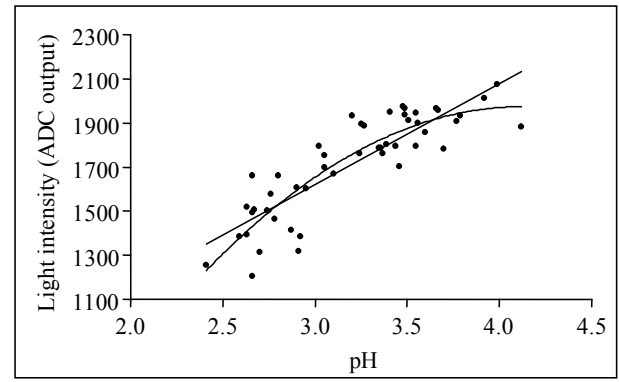

Fig. 6 Linear and quadratic relationship between the reflected light intensity measured by the OF-RS and $\mathrm{pH}$ of carambola.

For the firmness measurement, the response algorithm was best developed by linear regression. The linear representation (Fig. 7) of the carambola firmness measurement is expressed in (6) with $R=$ 0.872 and $R M S E=0.909 \mathrm{kgf}$.

$$
\begin{gathered}
\text { Firmness }=15.3-0.00671 R_{635} \\
R=0.872 ; R M S E=0.909 \mathrm{kgf} .
\end{gathered}
$$

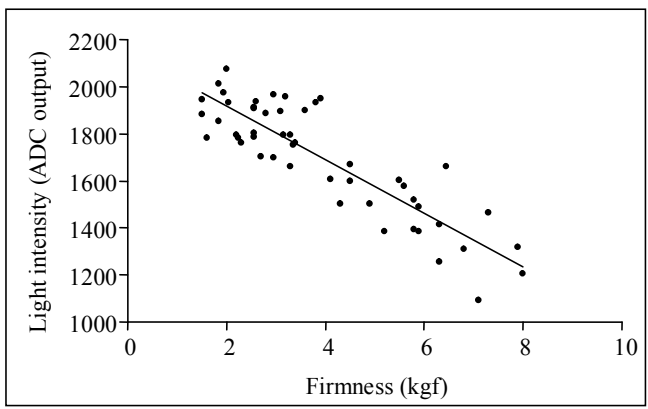

Fig. 7 Linear relationship between the reflected light intensity measured by the OF-RS and firmness of carambola.

The OF-RS successfully produced significant results in the measurement of the carambola $\mathrm{pH}$ and firmness with $R$ between 0.861 and 0.872 . The system performance was comparable with the measurement produced by the individual wavelength analysis using the Jaz spectrometer, as shown in Fig.
4. A higher measurement performance can be expected if the current LED that operates at the peak wavelength of $635 \mathrm{~nm}$ is replaced by a higher intensity LED with a peak wavelength at closer to $675 \mathrm{~nm}$ (the most suitable wavelength for the measurement of chlorophyll in carambola [41]), which is also proven as the highest efficient wavelength to determine the carambola intrinsic quality. In the research conducted by French et al. [42], they have identified the peak absorbance for chlorophyll at $661.6 \mathrm{~nm}, 669.6 \mathrm{~nm}, 677.1 \mathrm{~nm}$, and $683.7 \mathrm{~nm}$. On the other hand, several researchers have concluded absorbance bands for chlorophyll in the determination of the fruits' intrinsic quality. For instance, wavelengths at $672 \mathrm{~nm}$ and $680 \mathrm{~nm}$ have been identified by Gomez et al. [18] and Kawano et al. [43] as the peak absorbance for mandarin oranges while $673 \mathrm{~nm}$ has been identified by Cao et al. [13] as the peak absorbance for grapes. These stand as the evidence that the developed optical fiber sensor, OF-RS, can also be used to evaluate intrinsic quality parameters of different fruits via their chlorophyll content.

Next, this section will discuss the application of the OF-NIRS which has been applied for the measurement of the carambola $\mathrm{pH}$ and firmness. For the measurement of the carambola $\mathrm{pH}$, the response algorithm was best generated only by quadratic regression (Fig. 8) and is expressed in (7) with $R=$ 0.751 and $R M S E=0.293 \mathrm{pH}$.

$$
\begin{gathered}
p H=5.035-0.001221 R_{880}+0.0000001 R_{880}{ }^{2} \\
R=0.751 ; R M S E=0.293 \mathrm{pH} .
\end{gathered}
$$

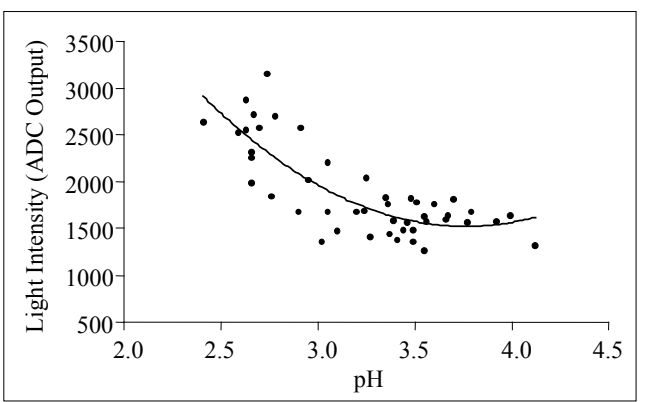

Fig. 8 Quadratic relationship between the reflected light intensity measured by OF-NIRS and $\mathrm{pH}$ of carambola. 
For the carambola firmness measurement, the response algorithm was best developed through cubic regression (Fig. 9) and is expressed in (8) with $R=0.773$ and $R M S E=1.207 \mathrm{kgf}$.

$$
\begin{gathered}
\text { Firmness }=18.94-0.02705 R_{880}+ \\
0.000014 R_{880}{ }^{2}-0.0000001 R_{880}{ }^{3} \\
R=0.773 ; R M S E=1.207 \mathrm{kgf.}
\end{gathered}
$$

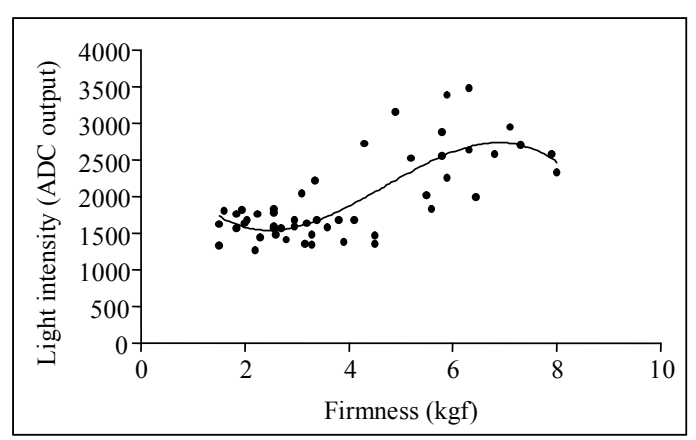

Fig. 9 Cubic relationship between the reflected light intensity measured by the OF-NIRS and firmness of carambola.

The OF-NIRS produced satisfactory results for the carambola $\mathrm{pH}$ and firmness measurements with $R$ over 0.75 . Even if the single system performance results obtained were considered low, the exciting finding from this experiment revealed that the results obtained are very closely related to the measurement produced by individual wavelength analysis using the Jaz spectrometer, as shown in Fig. 5 , which were also generated through quadratic and cubic regressions. The combination of the OF-RS and OF-NIRS results for the carambola $\mathrm{pH}$ and

Table 3 Summary of results obtained from optical fiber sensors.

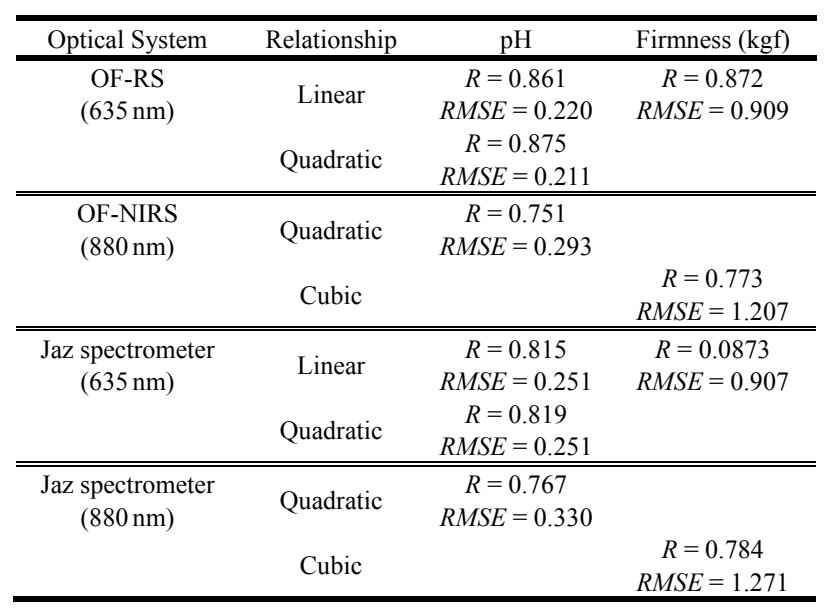

firmness measurements through multiple linear regression did not produce any improvements in the measurement accuracy. The complete measurement results obtained in this research are listed in Table 3.

\section{Conclusions}

From the comparative analysis, the results obtained through the optical fiber sensors were almost similar to those measured using the Jaz spectrometer. For the measurement of intact carambola $\mathrm{pH}$, the OF-RS showed more accurate results than the Jaz spectrometer at the wavelength of $635 \mathrm{~nm}$. In summary, using spectroscopy, the combination of the optical components of the OF-RS and OF-NIRS has been proven capable of producing optimum results for the measurement of the $\mathrm{pH}$ and firmness of carambola, which were comparable with those of the commercial spectroscopy instrumentation. The followings are the advantages of using the optical fiber sensors for the measurement of the fruit intrinsic quality:

(1) It has a much lower cost [approximately USD 300 for the optical fiber sensors, OF-RS, and OF-NIRS (without the fiber probe) versus approximately USD 5,000 for the Jaz spectrometer and tungsten halogen lamp (without the fiber probe and sampling facilities)].

(2) It can produce the instantaneous reading with only about $2 \mathrm{~s}$ of individual measurement execution time. The system can also produce the online reading with execution time of less than $0.1 \mathrm{~s}$. Typical commercial spectrometers require the intensive data processing and application of tedious mathematical analysis of the raw spectra.

(3) It is easy to operate with the minimal amount of training. Commercial spectrometers can only be operated by workers well trained in optical instrumentation and software application.

(4) It has less complexity in terms of the system structure because it is only operated by LEDs and detectors that contribute directly to the measurement of the fruit intrinsic quality. The application of LEDs 
has eliminated the need for bandpass filters. Commercial spectrometers have a broad array of wavelengths that are neglected because they do not contribute to the developed measurement algorithm.

Further research can be expanded in several areas to increase the efficiency of the optical fiber sensor. The application of LEDs with various characteristics such as different wavelengths within the visible and NIR regions and narrower spectral width and higher emission intensity, especially within the NIR region, could identify the best configuration that can generate higher measurement accuracy. The optical fiber system with sequential LED triggering from one wavelength to another will be required if the measurement of multiple wavelengths is made at precisely the same location on the intact fruit sample. The success of the specialized optical fiber sensor for the measurement of the fruit intrinsic quality can positively benefit fruit growers and allow the transformation of the current definition of the fruit quality from the physical attribute-based evaluation to intrinsic assessment.

\section{Acknowledgement}

This project is sponsored by Universiti Sains Malaysia Research University Grant (Grant no. 1001/PFIZIK/811153), Research University Postgraduate Research Grant Scheme (Grant No. 1001/PJJAUH/843028) and Malaysian Federal Agricultural Marketing Authority (FAMA).

Open Access This article is distributed under the terms of the Creative Commons Attribution License which permits any use, distribution, and reproduction in any medium, provided the original author(s) and source are credited.

\section{References}

[1] M. Ruiz-Altisent, J. Ortiz-Cañavate, and C. Valero,
"Fruit and vegetables harvesting systems," in Production Practices and Quality Assessment of Food Crops, vol. 1, R. Dris and S. M. Jain Ed. Netherlands: Kluwer Academic Publishers, 2004, pp. 261-285.

[2] C. Valero and M. Ruiz-Altisent, "Design guidelines for a quality assessment system of fresh fruits in fruit centers and hypermarkets," Agricultural Engineering International: the CIGR Journal of Scientific Research and Development (International Commission of Agricultural Engineering), vol. 2, pp. 1-20, 2000.

[3] P. Barreiro, M. Ruiz-Altisent, C. Valero, and J. Garcia-Ramos, "Fruit postharvest technology: instrumental measurement of ripeness and quality," in Production Practices and Quality Assessment of Food Crops, vol. 3, R. Dris and S. M. Jain Ed. Netherlands: Kluwer Academic Publishers, 2004, pp. 321-340.

[4] S. Huyskens-Keil and M. Schreiner, "Quality dynamics and quality assurance of fresh fruits and vegetables in pre- and posharvest," in Production Practices and Quality Assessment of Food Crops, vol. 3, R. Dris and S. M. Jain Ed. Netherlands: Kluwer Academic Publishers, 2004, pp. 401-449.

[5] S. H. Noh and K. H. Choi, "Non destructive quality evaluation technology for fruits and vegetables," presented at International Seminar on Enhancing Export Competitiveness of Asian Fruits, Bangkok, Thailand, May 18-19, 2006.

[6] T. Temma, K. Hanamatsu, and F. Shinoki, "Measuring the sugar content of apples and apple juice by near infrared spectroscopy," Optical Review, vol. 9 no. 2, pp. 40-44, 2002.

[7] P. Chen and Z. Sun, "A review of non-destructive methods for quality evaluation and sorting of agricultural products," Journal of Agricultural Engineering Research, vol. 49, pp. 85-98, 1991.

[8] H. Gao, F. Zhu, and J. Cai, "A review of non-destructive detection for fruit quality," Computer and Computing Technologies in Agriculture III, IFIP Advances in Information and Communication Technology, vol. 317, pp. 133-140, 2010.

[9] X. Li and Y. He, "Non-destructive measurement of acidity of Chinese bayberry using Vis/NIRS techniques," European Food Research and Technology, vol. 223, no. 6, pp. 731-736, 2006.

[10] M. W. Davey, W. Saeys, E. Hof, H. Ramon, R. L. Swennen, and J. Keulemans, "Application of visible and near-infrared reflectance spectroscopy (Vis/NIRS) to determine carotenoid contents in banana (Musa spp.) fruit pulp," Journal of Agricultural and Food Chemistry, vol. 57, no. 5, pp. 1742-1751, 2009.

[11] G. Fan, J. Zha, R. Dub, and L. Gao, "Determination of soluble solids and firmness of apples by Vis/NIR transmittance," Journal of Food Engineering, vol. 93, no. 4, pp. 416-420, 2009.

[12] C. Camps and D. Christen, "Non-destructive 
assessment of apricot fruit quality by portable visible-near infrared spectroscopy," LWT-Food Science and Technology, vol. 42, no. 6, pp. 1125-1131, 2009.

[13] F. Cao, D. Wu, and Y. He, "Soluble solids content and $\mathrm{pH}$ prediction and varieties discrimination of grapes based on visible-near infrared spectroscopy," Computers and Electronics in Agriculture, vol. 71, supplement 1, pp. S15-S18, 2010.

[14] M. Valente, R. Leardi, G. Self, G. Luciano, and J. P. Pain, "Multivariate calibration of mango firmness using Vis/NIR spectroscopy and acoustic impulse method," Journal of Food Engineering, vol. 94, no. 1, pp. 7-13, 2009

[15] Y. Shao, Y. Bao, and Y. He, "Visible/near-infrared spectra for linear and nonlinear calibrations: a case to predict soluble solids contents and $\mathrm{pH}$ value in peach," Food Bioprocess Technology, vol. 4, no. 8, pp. 1376-1383, 2011.

[16] L. S. Magwaza, U. L. Opara, H. Nieuwoudt, P. J. R. Cronje, W. Saeys, and B. Nicolaï, "NIR spectroscopy applications for internal and external quality analysis of citrus fruit - a review," Food and Bioprocess Technology, vol. 5, no. 2, pp. 425-444, 2011.

[17] T. Sun, K. Huang, H. Xu, and Y. Ying, "Research advances in nondestructive determination of internal quality in watermelon/melon: a review," Journal of Food Engineering, vol. 100, no. 4, pp. 569-577, 2010.

[18] A. H. Gomez, Y. He, and A. G. Pereira, "Non-destructive measurement of acidity, soluble solids and firmness of satsuma mandarin using Vis/NIR spectroscopy techniques," Journal of Food Engineering, vol. 77, no. 2, pp. 313-319, 2006.

[19] V. Gonzalez-Caballero, M. T. Sanchez, M. I. Lopez, and D. Perez-Marín, "First steps towards the development of a non-destructive technique for the quality control of wine grapes during on-vine ripening and on arrival at the winery," Journal of Food Engineering, vol. 101, no. 2, pp. 158-165, 2010.

[20] V. A. McGlone and S. Kawano, "Firmness, dry matter and soluble solids assessment of postharvest kiwifruit by NIR spectroscopy," Postharvest Biology and Technology, vol. 13, no. 2, pp. 131-141, 1998.

[21] P. C. Williams, "Implementation of near-infrared technology," in Near-Infrared Technology in the Agricultural and Food Industries, P. C. Williams and K. H. Norris Ed. St Paul MN: The American Association of Cereal Chemists, 2001, pp. 145-169.

[22] Y. Shao and Y. He, "Nondestructive measurement of the internal quality of bayberry juice using Vis/NIR spectroscopy," Journal of Food Engineering, vol, 79, no. 3, pp. 1015-1019, 2007.

[23] B. M. Nicolai, K. Beullens, E. Bobelyn, A. Peirs, W. Saeys, K. I. Theron, et al., "Nondestructive measurement of fruit and vegetable quality by means of NIR spectroscopy: a review," Postharvest Biology and Technology, vol. 46, no. 2, pp. 99-118, 2007.

[24] P. P. Subedi, K. B. Walsh, and G. Owens, "Prediction of mango eating quality at harvest using short-wave near infrared spectrometry," Postharvest Biology and Technology, vol. 43, no. 3, pp. 326-334, 2007.

[25] P. Williams and K. Norris, Near-infrared technology in the agricultural and food industries. St. Paul MN: The American Society of Cereal Chemists, 1987, pp. 246.

[26] S. Saranwong, J. Sornsrivichai, and S. Kawano, "Prediction of ripe-stage eating quality of mango fruit from its harvest quality measured non-destructively by near infrared spectroscopy," Postharvest Biology and Technology, vol. 31, pp. 137-145, 2004.

[27] F. Liu, Y. He, L. Wang, and H. M. Pan, "Feasibility of the use of visible and near infrared spectroscopy to assess soluble solids content and $\mathrm{pH}$ of rice wines," Journal of Food Engineering, vol. 83, no. 3, pp. 430-435, 2007.

[28] C. Abrahamsson, J. Johansson, A. Sparen, and F. Lindgren, "Comparison of different variable selection methods conducted on NIR transmission measurements on intact tablets," Chemometrics and Intelligent Laboratory Systems, vol. 69, no. 1-2, pp. 3-12, 2003.

[29] L. Huang, D. Wu, H. Jin, J. Zhang, Y. He, and C. Lou, "Internal quality determination of fruit with bumpy surface using visible and near infrared spectroscopy and chemometrics: a case study with mulberry fruit," Biosystems Engineering, vol. 109, no. 4, pp. 377-384, 2011.

[30] F. Chauchard, R. Cogdill, S. Roussel, J. M. Roger, and V. Bellon-Maurel, "Application of LS-SVM to non-linear phenomena in NIR spectroscopy: development of a robust and portable sensor for acidity prediction in grapes," Chemometrics and Intelligent Laboratory Systems, vol. 71, no. 2, pp. 141-150, 2004.

[31] M. Tsuta, J. Sugiyama, and Y. Sagara, "Near-Infrared imaging spectroscopy based on sugar absorption band for melons," Journal of Agricultural and Food Chemistry, vol. 50, no. 1, pp. 48-52, 2002.

[32] M. F. Ahmad Kamil, M. Mokji, U. U. Sheikh, and S. A. R. Abu-Bakar, "Machine vision for starfruit (averrhua carambola) inspection," in IEEE Conference Proceedings, 2010 Fourth Asia International Conference on Mathematical/ Analytical Modelling and Computer Simulation, Kota Kinabalu, Malaysia, May 26-28, pp. 333-336, 2010.

[33] Ministry Of Agriculture \& Agro-Based Industry Malaysia, Agrofood Statistics 2010. Selangor, Malaysia: Ministry Of Agriculture \& Agro-Based Industry, 2010, pp. 42. 
[34] M. Z. Abdullah, A. S. Fathinul-Syahir, and B. M. N. Mohd-Azemi, "Automated inspection system for colour and shape grading of starfruit (averrhoa carambola L.) using machine vision sensor," Transactions of the Institute of Measurement \& Control, vol. 27, no. 2, pp. 65-87, 2005.

[35] M. Z. Abdullah, J. Mohamad-Saleh, A. S. Fathinul-Syahir, and B. M. N. Mohd-Azemi, "Discrimination and classification of fresh-cut starfruits (averrhoa carambola L.) using automated machine vision system," Journal of Food Engineering, vol. 76, no. 4, pp. 506-523, 2006.

[36] R. Amirulah, M. M. Mokji, and Z. Ibrahim, "Starfruit color maturity classification using $\mathrm{Cr}$ as feature," in IEEE Conference Proceedings 2010 Sixth International Conference on Signal-Image Technology and Internet Based Systems, Kuala Lumpur, Malaysia, Dec. 15-18, pp. 93-97, 2010.

[37] Federal Agricultural Marketing Authority, Grade specifications and standards. Selangor, Malaysia: Ministry Of Agriculture \& Agro-Based Industry, 2008.

[38] A. F. Omar and M. Z. MatJafri, "Turbidimeter design and analysis: a review on optical fiber sensor for the measurement of water turbidity," Sensors, vol. 9, no. 10, pp. 8311-8335, 2009.
[39] G. P. Krivoshiev, R. P. Chalucova, and M. I. Moukarev, "A possibility for elimination of the interference from the peel in nondestructive determination of the internal quality of fruit and vegetables by VIS/NIR spectroscopy," LWT-Food Science and Technology, vol. 33, no. 5, pp. 344-353, 2000.

[40] P. N. Schaare and D. G. Fraser, "Comparison of reflectance, interactance and transmission modes of visible-near infrared spectroscopy for measuring internal properties of kiwifruit (actinidia chinensis)," Postharvest Biology and Technology, vol. 20, no. 2, pp. 175-184, 2000.

[41] A. F. Omar, H. Atan, and M. Z. MatJafri, "Visible spectral linearisation, gradient shift and normalisation in quantifying carambola acidity," Food Biophysics, vol. 7, no. 4, pp. 289-295, 2012.

[42] C. S. French, J. S. Brown, and M. C. Lawrence, "Four universal forms of chlorophyll a," Plant Physiology, vol. 49, no. 3, pp. 421-429, 1972.

[43] S. Kawano, T. Fujiwara, and M. Iwamoto, "Nondestructive determination of sugar content in satsuma mandarin using near infrared (NIR) transmittance," Journal of the Japanese Society for Horticultural Science, vol. 62, no. 2, pp. 465-470, 1993. 